ojs.uv.es/index.php/qdfed

Rebut: 02.06.2020. Acceptat: 25.06.2020

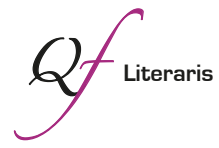

Per a citar aquest article: Gilabert, Gaston. 2020. "El oráculo saboteado: ideología y comportamientos guiados en la comedia áurea”. Quaderns de Filologia: Estudis Literaris XXV: I39-156.

doi: $10.7203 /$ qdfed.25.18995

\title{
El oráculo saboteado: ideología y comportamientos guiados en la comedia áurea
}

The sabotaged oracle: ideology and guided behaviors in the Spanish Golden Age comedia

Gaston Gilabert

Universitat de Barcelona

gastongilabert@ub.edu

Resumen: Este artículo propone un análisis del género teatral áureo en uno de sus mecanismos retóricos con mayor capacidad performativa: la función dramática oracular a partir de la cual una voz superior -sea un oráculo, un sueño, una voz interior o cualquier otra posesión transitoria- es escuchada simultáneamente por el receptor-personaje y por el receptor-público. El dramaturgo jerarquiza así la heterogeneidad de discursos presentes en el microcosmos de la comedia y, ofreciendo un silogismo epistemológico, incita a actuar directamente al primero y metonímicamente al segundo. La crítica entendida como sabotaje ofrece unas herramientas críticas que permiten desenmascarar los entresijos de estos recursos oraculares que imponen un modelo de mundo a los destinatarios del mayor espectáculo de masas de la temprana modernidad.

Palabras clave: teatro; poder; oráculos; sabotaje; Siglo de Oro.

Abstract: This article proposes an analysis of the Siglo de Oro theatrical genre in one of its rhetorical mechanisms with greater performative capacity: the oracular dramatic function from which a higher voice -be it an oracle, a dream, an inner voice or any other transitory possessionis simultaneously heard by the receiver-character and by the receiver-public. The playwright thus hierarchizes the heterogeneity of discourses present in the microcosm of the play and, offering an epistemological syllogism, encourages the first to act directly and the second metonymically. Criticism understood as sabotage offers critical tools that allow to unmask the ins and outs of these oracular resources that impose a world model on the recipients of the greatest mass show of early modernity.

Keywords: theatre; power; oracles; sabotage; Siglo de Oro. 


\section{Modernidad, teatro y sabotaje}

El objetivo de este trabajo es realizar un ejercicio crítico a propósito del teatro del Siglo de Oro que retoma el enfoque que planteara Maravall (I972) y lo actualiza a la luz del desarrollo de los estudios filosóficos, teórico-literarios y culturales posteriores. Asimismo, en estas páginas se plantea una tesis acerca de lo que he llamado función dramática oracular, por la que agrupo una serie de recursos apelativos vinculados con una voz superior que jerarquiza y proyecta un fuerte contenido ideológico con el objetivo de imponer una visión del mundo determinada a las dramatis personae y a los espectadores.

Si desde Althusser (I974: 52) puede definirse la ideología como una representación de la relación imaginaria de un individuo con sus condiciones reales de existencia, se entiende que la literatura juegue un papel especial al aportar paradigmas éticos y de acción ficticios pero sin embargo aplicables a la realidad fenoménica del lector. Por tanto, no hay nada más ideológico y modelizador de la subjetividad del individuo que ese trasvase entre mundos basado en la analogía de sus reglas: las lentes precodificadas por el autor literario están diseñadas para que encajen en la anatomía del receptor y para que, al cerrar el libro, encuentre a su alrededor nuevos matices que dan sentido a su mundo sin saber que son las lentes las que los han creado. Que esa percepción inducida pase desapercibida, por natural, es el mayor éxito de todo aparato ideológico, porque ese lector propagará el modelo epistemológico al generar sus propios discursos y acciones aparentemente inocuos. El proceso descrito no tiene por qué ser nocivo per se, máxime si la especie humana está programada para consumir discursos de todo tipo -y no solo literarios- desde antes de tener uso de la razón. No obstante, es necesario ser consciente de que la cultura no es políticamente inocente y, aunque puede también ofrecer modelos liberadores, a menudo ha sido y es utilizada en clave contraria por la clase dominante con el objetivo de mantener una situación de privilegio, haciendo que sus valores se conviertan en hegemónicos e incluso sean compartidos por los oprimidos ${ }^{\mathrm{I}}$.

El discurso ficticio cobra carta de naturaleza y tiene efectos en la realidad individual del sujeto, sobre todo cuando cuenta con la sanción institucional,

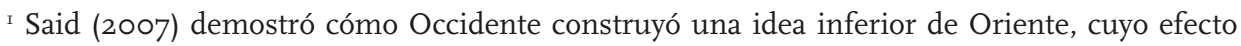
fue legitimar una situación de dominación que logró que los dominados se identificaran con la imagen ficticia que los europeos habían creado para ellos, atrayéndolos, por tanto, a la defensa de un sistema que los oprimía.
} 
pues así llega a aclimatarse en el pueblo y lo que era imaginario termina deviniendo normativo y de obligada observancia ${ }^{2}$. La sutileza en la transmisión de la ideología estriba en que, si bien los agentes de la represión son fácilmente identificables y tienen una organización clara, los agentes de la ideología en cambio están diseminados, parecen funcionar autónomamente y en la mayoría de casos no son ni siquiera conscientes de su papel en el mantenimiento de las relaciones de poder hegemónicas ${ }^{3}$. No obstante, la intensidad de estas prácticas de poder debería dejarse traslucir más claramente en los procesos históricos en que la alteridad es vista como una amenaza directa para los objetivos de la élite. Así lo demuestra el análisis de Said a partir de la experiencia cultural del imperialismo de Occidente. En algunos casos límite -de especial interés para el desmantelamiento de los discursos hegemónicos- está en juego la propia supervivencia de la estructura de poder hasta tal punto que necesita movilizar y potenciar al máximo todos los aparatos ideológicos a su alcance. Aquí es donde se hace necesario hablar del papel del teatro del Siglo de Oro en la crisis no tan dorada que trae consigo la modernidad.

Asensi (20II) demuestra el poder subversivo que puede tener la crítica para desmantelar la autoridad represiva de aquellos discursos que, con sus falsos silogismos, modelan nuestra manera de percibir el mundo y nos incitan a pensar y actuar de acuerdo con la ideología dominante. Las bases de su mirada crítica se asientan sobre numerosos ejemplos, algunos extraídos de la literatura española del Siglo de Oro, fundamentalmente vinculados a los géneros de la prosa (Quijote, Lazarillo), pero también a los de la poesía (Santa Teresa, Góngora) ${ }^{4}$. Por eso mismo, resulta llamativo que la literatura dramática, uno de los grandes géneros del Siglo de Oro, no haya sido objeto de la misma atención, es decir, no se tenga en cuenta un conjunto de textos

\footnotetext{
${ }^{2}$ Es elocuente la distinción de Gramsci entre la sociedad política y la sociedad civil, según la cual las instituciones coercitivas del primer conjunto no tienen por qué ser más eficaces para mantener una situación opresiva que los consensos alcanzados por el segundo, de manera que la sociedad civil (medios de comunicación, academias de artistas y cualquier plataforma de intelectuales) tiene un papel fundamental para construir esa supremacía cultural que el filósofo italiano denomina hegemonía, y que va a marcar el horizonte de usos y costumbres de una sociedad determinada en detrimento de otras formas de cultura (I975: 40-4I y 58-59).

${ }^{3}$ Sigue vigente la máxima althusseriana según la cual "ninguna clase puede tener en sus manos el poder de Estado en forma duradera sin ejercer al mismo tiempo su hegemonía sobre y en los aparatos ideológicos de Estado" (I974: 32).

4 De hecho, su obra señera debe mucho a este período de la historia de la literatura, pues surgió, como el crítico asegura, "de la risa que provoca el acto de lectura de Don Quijote de la Mancha" (Asensi, 20II: 7), en que parafrasea al Foucault lector de Borges.
} 
valiosísimos que configura el primer gran sistema de comunicación de masas de la modernidad, aquel que sedujo al primer Cervantes, mucho antes de que concibiera a su caballero andante, y que Lope de Vega llevó a todos los rincones de la península, condensando este arte en una fórmula eficaz para atraer la atención del público.

Independientemente de la predilección de Asensi en la configuración del corpus de géneros literarios y obras concretas, lo que quiere destacarse en este trabajo es que el dispositivo teatral admite a la perfección las preguntas de la crítica entendida como sabotaje y que, más allá de su operatividad, abre nuevas vías de interpretación por la complejidad de su recepción dual en tanto que texto y espectáculo de masas. Estamos ante una realidad discursiva cuyo análisis no se agota en la lectura de una secuencia de palabras, pues su conjunto configura un artefacto especialmente diseñado para convertirse en un material vivo que, en virtud de la mímesis, se despliega sin aparentes intermediarios ante una sedienta congregación de espectadores letrados e iletrados. Por tanto, la capacidad para imponer modelos de mundo es de mucho mayor alcance en el teatro que en el resto de los géneros literarios del Siglo de Oro.

El declive del antiguo régimen feudal, el descubrimiento de América, la revolución espiritual de la reforma protestante, el desarrollo de los studia humanitatis y los avances científicos vinculados con la cosmología son solo ejemplos de factores que provocan una confianza en el hombre moderno capaz de desafiar la tutela y la relación de poder de aquellas instituciones que parecían incontestables en su presunta infalibilidad5. No juzgo como casualidad que esta crisis coincida en toda Europa con la profesionalización de compañías de actores, la construcción de edificios para albergar espectáculos y el desarrollo de todo un sistema teatral con vocación de universalidad. Del mismo modo, sería una ingenuidad tomar por mero azar que al mismo tiempo se dé el pistoletazo de salida a la conformación de los Estados absolutos, mediante la eliminación de la pluralidad de prácticas políticas medievales, la subyugación de sus agentes y la búsqueda de nuevos dispositivos de control y de legitimidad.

Independientemente del carácter consciente en el uso como tal por parte de los dramaturgos -la inercia es también una fuerza-, el teatro del Siglo de

\footnotetext{
5 Fontana (2000: 89-107) ha explicado cómo la crisis que arranca con la modernidad pone en jaque la legitimidad esgrimida hasta el momento entre las élites gobernantes, y, por ello, estas lanzan una ofensiva para reconquistar a las clases populares y atraerlas a un nuevo consenso mediante la cultura oficial o la represión.
} 
Oro, epicentro de la cultura de masas de la modernidad y generador de patrones de conducta, se revela en su potencia como uno de los instrumentos ideológicos más suculentos para apuntalar la hegemonía de los nacientes Estados absolutos y evitar la desfiguración de la pirámide estamental ${ }^{6}$. El teatro, al pretender ser imago mundi, sobrepasa los límites de un aparato cultural y se convierte en imagen viva de todos los aparatos ideológicos y de sus respectivos agentes, que asisten como espectadores y se ven reflejados en un espejo que los interpela. La masa de espectadores iletrados, frecuentemente aludidos en el Siglo de Oro como "el vulgo", no estaba acostumbrada al consumo de ficción, en consecuencia, en esa infancia de la mímesis dramática de la modernidad, no resultaba fácil distinguir netamente la realidad de su imitación?. El rédito político que la clase dominante sacó de esta inocencia debió de ser mayúsculo.

Obsérvese la gran diferencia existente entre una novela o un poema destinado a ser leído, con el arte dramático. La recepción por parte del lector solo es una primera fase en este género literario ya que, al devenir luego espectáculo de masas, se da un giro radical en el proceso comunicativo que redunda en beneficio de la confusión entre realidad ficticia y realidad fenoménica. La autoridad represiva del discurso puede ser por tanto más eficiente. En la segunda fase, el receptor interpelado es el actor, y la fuente del discurso ya no es solo un conjunto de símbolos de tinta sobre un papel, sino sobre todo el actor principal, cabeza de compañía o el que ejecute las funciones de director de

\footnotetext{
${ }^{6}$ Althusser sintetizó en ocho las instituciones que conforman aparatos ideológicos del Estado: los religiosos, los escolares, los familiares, los jurídicos, los políticos, los sindicales, los de información y los culturales (I974: 28). Pareciera que el espectáculo dramático solo formara parte de esta última categoría, y así es en esencia, pero no debe olvidarse que el papel que cumplía el teatro en la temprana modernidad rebasaba los límites de su estricto campo para cumplir una misión proteica: unas veces era religioso y en sus dramas litúrgicos, comedias hagiográficas y autos sacramentales, aun fuera del templo, iluminaba con sus dogmas y sacramentos, otras veces su asunto era profano y en virtud de la mímesis se presentaban imitados de la realidad los más diversos problemas familiares, jurídicos, políticos y económicos. Sin contar las escenas en que los actores representaban procesos de aprendizaje, todo el teatro era escuela para los espectadores antes de la escolarización obligatoria y el lema delectare et prodesse funcionaba como principio rector. Acudir al corral una tarde de comedias formaba parte del ritual de socialización en el Siglo de Oro y uno podía informarse de las novedades acaecidas, cuando no eran aludidas por los actores en guiños a su presente o directamente no se escenificaban hechos de la historia reciente con función de noticiero.

7 Lope de Vega, en dos lugares distintos (2016: vv. 330-337 y I965: 92-93), refiere que el vulgo trasladaba sus juicios éticos del personaje a la persona, confundiendo a los actores de paisano con los papeles que interpretaban sobre las tablas.
} 
escena. Así, el largo tiempo que se precisa para que un discurso ficcional se convierta en normativo aquí se acelera y los actores se ven obligados a actuar según una interpretación subjetiva del texto dramático. Ya no se trata de esperar a que el ciudadano ejecute acciones conforme un modelo de mundo leído, sino que el sistema teatral funciona de suyo como una metonimia de ese proceso epistemológico. A cambio de dinero se logra la adhesión de los actores a un guion y a las directrices marcadas para que desplieguen ante los espectadores aquello que más desea el poder: un discurso y un rol tan bien actuado que parece natural, a partir del que el intérprete, fiel a su papel, pasa a vivir su realidad obrando según una ética y un modelo de mundo muy determinados. La naturalización del silogismo consiste en ocultar tanto la segunda fase como la primera, es decir, los ensayos dirigidos y el texto dramático, para que los actores, seres hechos del mismo material que los espectadores, cumplan con aparente autonomía y espontaneidad el papel que les ha sido asignado, generando una imagen especular que facilita que el público resbale con mayor facilidad ante el paradigma observado y se deslice hacia la repetición del patrón. Paradójicamente, los que están forzados a actuar deben fingir no estarlo en escena para que, en virtud de la mímesis, terminen forzando a aquellos que no tienen por oficio la imitación. He aquí la distinción fundamental con el resto de discursos provenientes de otros géneros literarios: el receptor último solo tiene que trasladar a su mundo lo que ya se ha producido en él, aunque con otro estatuto que no alcanza a delimitar con precisión. La tesis de Derrida (I986) acerca del privilegio de lo oral por encima de lo escrito en el marco del fonocentrismo occidental podría iluminar aquí la necesidad de invisibilizar el texto teatral en una representación o calificarlo de suplemento, ya que la huella escrita, esto es, el libro de instrucciones, evidenciaría tanto el carácter autoritario del discurso, como el proceso de traducción realizado para que esas manchas de tinta sean aptas para el consumo por parte de esa masa mayoritariamente analfabeta del Siglo de Oro $^{8}$.

\footnotetext{
${ }^{8}$ Además, la oralidad propia de la puesta en escena está ocultando que el desenlace de los personajes no es el resultado de las decisiones y acciones que ejecutan en las tablas, sino que su destino ya está escrito de acuerdo con el lugar que a cada uno le corresponde en una sociedad ordenada según el criterio del poder hegemónico, en una imagen de libertad que se quiere para el pueblo y que, en efecto, se está imponiendo en directo sin que se noten los hilos. Esto no significa que el espectador sea una tabula rasa cuando llega al teatro, sino que antes ya ha sido objeto de toda una red de prácticas constituyentes de subjetividad que han imprimido en él un modo de ser y de actuar como, por ejemplo, la que le ha indicado que acudir esa tarde al corral de comedias es una recreación propia de su condición y que una obra de ese tipo será de su agrado según su estado anímico. Cervantes dice que "el principal intento que las repúblicas or-
} 
Maravall, al calor de los avances de la crítica de la cultura de los años sesenta y setenta, postula en I972 una teoría sistemática por la que concibe todo el teatro del Siglo de Oro como una campaña de propaganda monárquico-señorial con el objetivo de atraer a las clases populares para la defensa de un sistema que se había visto amenazado por la ola transformadora de la modernidad (I972: 22). Se fija por ejemplo en el personaje tipo del labrador rico, al que la comedia recompensa su fidelidad al mantenimiento de la ideología hegemónica dotándolo de honor -epicentro de la cultura española del Barroco- y haciendo que él o sus hijos se vean ennoblecidos con un ascenso simbólico de clase social (1972: 63-79) ${ }^{9}$. Evidentemente, se trata de un espejismo que impone en las mentes de los espectadores una idea de mundo en que ciertas "virtudes" deben ser practicadas, haciéndoles albergar falsas esperanzas de una promoción social que dependerá en último término de la gracia o el capricho del rey.

La monarquía funciona, por tanto, como deus ex machina, un ente que pone paz al caos creado por unos vasallos díscolos y cuya regia sanción es imprescindible para cualquier propuesta de cambio social o político, incluso en los casos de revuelta popular contra la autoridad, de la misma manera que hoy debe pedirse permiso a la autoridad gubernamental para ejercer el derecho a manifestarse contra ella, por paradójico que parezca. En estas situaciones escénicas se tensa el pacto de ficcionalidad que dicta la verosimilitud de cualquier acción revolucionaria y, en consecuencia, es donde más se percibe esa mano invisible que intenta imponer con calzador un modelo de comportamiento a los súbditos potencialmente subversivos. En el ideal de la comedia cualquier transformación del estado de cosas además de estar a priori condenada al fracaso, siempre precisará de la sanción institucional. Piénsese en cómo los aldeanos de Fuenteovejuna, tras la revuelta que acaba con el asesinato del comendador que los tiranizaba, esperan en el desenlace la decisión final de los Reyes Católicos. Su primera reacción es castigar con una pena ejemplar a los responsables y por ello mandan a un juez inquisidor para que torture a la población hasta conseguir esos nombres. Como es

denadas tienen permitiendo que se hagan públicas comedias es para entretener la comunidad con alguna honesta recreación y divertirla a veces de los malos humores que suele engendrar la ociosidad." (2005: 496).

9 Así lo expresa Maravall: "el hombre que en su medio aldeano respeta al soberano y al orden social que en éste culmina, es rico y virtuoso, vive feliz y, precisamente por esos méritos de acatamiento del orden, ascienden él o sus hijos, incluso casados con nobles por mano del rey, como en deslumbrantes ejemplos excepcionales les muestra la comedia" (I972: 76). 
sabido, la unión del pueblo hace que fracase la misión y, aunque los reyes se plantean matarlos a todos, deciden sobreseer el caso por falta de pruebas incriminatorias y hacerse personalmente con el poder del territorio hasta que no se nombre al siguiente comendador ${ }^{\mathrm{ro}}$. Los reyes solo actúan cuando la violencia se dirige de abajo arriba y nunca al revés. Toda la fuerza libertaria del modelo de mundo invocado a lo largo de la obra da un giro al final para que los espectadores vuelvan a sus casas recordando la moraleja y teniendo clara la distinción jerárquica entre la autoridad intermedia de un señor feudal y la que representan los reyes.

Calderón de la Barca diseña algo parecido para La vida es sueño, también en la última jornada, en el levantamiento y guerra civil que enfrenta a Segismundo, liberado de su encierro y apoyado por el pueblo, contra su padre -el rey Basilio- y sus hombres. A pesar de la victoria del primer grupo, Segismundo, en un giro radical, traiciona al colectivo que representaba, rindiéndose, ofreciendo su cabeza al rey por la desobediencia que supuso el levantamiento contra su autoridad y mandando aprisionar de por vida al soldado que lo liberó (I995: vv. 3297-330I ${ }^{\text {II. }}$. De las muchas traiciones que podríamos nombrar en este drama y que afecta a varios personajes principales, Calderón juega con el uso del término traidor hasta tal punto que termina siendo exclusivamente aplicable a los vasallos capaces de subvertir el sistema; empero, como toda la trama es una pasarela de miembros de la familia real con distintos grados de consanguinidad y el final feliz lo constituye una alianza entre las cúspides aristocráticas de cada una de las facciones, el dramaturgo debe ingeniárselas para buscar a algún personaje de clase popular y termina aplicando el castigo de cadena perpetua al personaje más que secundario del soldado. He aquí otro ejemplo de viraje argumental en el desenlace por el que se reconducen todas las aspiraciones de cambio a la voluntad del monarca amenazado. Es sintomático que el monólogo más célebre de Segismundo -y que un buen número de ciudadanos escolarizados en España y de distintas generaciones

\footnotetext{
${ }^{10}$ El sistema amenazado ha vuelto a su cauce y poco importa que el futuro señor cometa los mismos desmanes contra sus vasallos, pues el primero, Fernán Gómez, ya lo había hecho aun a sabiendas de los reyes Isabel y Fernando, que decidieron mirar a otro lado.

${ }^{\text {II }}$ El autor de este estudio tuvo la oportunidad de asistir al estreno de La vida es sueño por parte de la Compañía Nacional de Teatro Clásico, en el marco del Festival de Almagro de 20I2, y observó que estos versos finales de la obra habían sido suprimidos, con lo que el carácter conservador del desenlace quedaba atenuado. La versión del texto calderoniano estuvo a cargo del dramaturgo Juan Mayorga, estudioso de Benjamin y de su perspectiva sobre los vencedores y vencidos.
} 
conocemos de memoria: el que termina con los versos "que toda la vida es sueño, / y los sueños, sueños son" (Calderón de la Barca, I995: vv. 2I862I87)-, sea en realidad el detonante del giro conservador final, pues, en ese bello discurso el protagonista expresa ante el público que el lugar que a cada uno le corresponde en la vida terrenal es simplemente un papel sin importancia, sobre el que uno no debe obsesionarse ni cuestionarse, ya que este mundo es tan pasajero, breve y falaz como los sueños. Cuando la muerte nos haga despertar a la vida eterna ya seremos compensados por las injusticias soportadas, así que, espectadores, aguantad con el reparto de roles que os ha tocado. Habiendo entendido esta lección trascendente no nos extraña que en el desenlace Segismundo tome unilateralmente la decisión de frustrar la revolución apoyada por el pueblo. Al fin y al cabo, ¿qué importa que sea Segismundo quien termine sus días en el palacio como nuevo rey mientras el vasallo que lo liberó del encierro se pudre entre rejas, si toda la vida es sueño y la muerte nos igualará a todos? Aceptar este orden de factores como algo azaroso o natural y, en consecuencia, engullir el falso silogismo en que se sustenta la obra, implica arrodillarse como lectores o espectadores ante la autoridad represiva del discurso, habilitando los efectos de la imposición de tal modelo de mundo.

Esta interpretación no se fundamenta en el anacronismo de superponer una lectura de filosofía política propia de los siglos xx y xxi a un texto del Siglo de Oro, sino que aprovecha estas herramientas analíticas para desenmascarar la noción de obediencia que podrían tener autores como Calderón -formado, por cierto, en el Colegio Imperial de los jesuitas- en sintonía con su propio polisistema. Si no, juzgue el lector cuán bien encajan con las ideas aquí expuestas los postulados de Loyola, uno de los mayores exponentes de la Contrarreforma ${ }^{12}$.

\footnotetext{
${ }^{12}$ El fundador de la Compañía de Jesús dice "Debemos siempre tener, para en todo acertar, que lo blanco que yo veo, creer que es negro, si la Iglesia hierárchica assí lo determina" y asegura que la persona obediente debe ejercitar la mansedumbre y dejarse guiar por medio del superior "como si fuese un cuerpo muerto, que se dexa llevar adondequiera y trattar comoquiera, o como un bastón de hombre viejo". Asimismo, explica cómo sujetar el entendimiento con el dogma en las mentes más disidentes, desarrolla recursos silogísticos que homologan el poder de Dios con el de los hombres que actúan a su servicio, trata el funcionamiento aparentemente autónomo del obediente e incluso establece una analogía con las policías seglares (I963: 272, 53I y 8I4-8I6).
} 


\section{La función dramática oracular}

A nadie se le escapa el patrón de conducta que se dispara contra el espectador cuando la figura del rey sale en muchos desenlaces de comedia a restaurar el orden amenazado, determinando el destino de los personajes en escena, que viven esa imposición sobre ellos como una celebración de fin de fiesta. Más desapercibido pasa un conjunto de recursos todavía no estudiado y que las herramientas ofrecidas por la crítica entendida como sabotaje puede ayudar a desmantelar. Me estoy refiriendo a uno de los mecanismos retóricos con mayor capacidad performativa debido a la fuerza o violencia de su interpelación: la voz de un ente superior que se expresa a través de un oráculo, un sueño, una voz interior o cualquier otra posesión fugaz de carácter profano y que he agrupado bajo la denominación de recursos oraculares por ejecutar esta función dramática ${ }^{\text {13. }}$. Si se sigue la hipótesis que propongo, el campo de lo sobrenatural profano estaría explorando vías no miméticas -es decir, que denoten un poder mayor que el de un hombre ordenando una acción a otropara alcanzar y producir otro tipo de fieles, aquellos que deberán seguir la religión civil del omnipotente Estado absoluto encarnado por el rey, aun sin mediar ninguna orden explícita. Más allá de pretender la adhesión que estudió Maravall, estaríamos hablando de devoción, pues se estarían emulando los procedimientos ininteligibles cristianos -por ejemplo, los milagros- para, una vez modificada su semántica, arrastrar a la ciudadanía a una obediencia ciega dirigida a mantener el statu quo.

Podríamos dividir por tanto el elemento sobrenatural de las comedias áureas entre lo maravilloso secular o profano y lo maravilloso cristiano. El primer campo, de tradición más antigua, es el único que carece de una iglesia que monopolice la interpretación de sus procedimientos míticos, de ahí que se haya prestado siempre a una heterogeneidad de objetivos y resulte atractivo para sacralizar todo poder civil que se considere suprahumano, en una serie de correspondencias que van in crescendo en Europa desde la Edad Media a la Edad Moderna. Observando el caso peninsular, ya antes de la Casa de Austria, Alfonso X se había esforzado en utilizar el dispositivo discursivo de la historia para legitimar el rango de los monarcas hispánicos emparentándose con

\footnotetext{
${ }^{13}$ Excluyo deliberadamente el ámbito de lo cristiano escogiendo estos recursos en comedias que no pertenecen a ningún subgénero dramático de tipo religioso y en los que, por tanto, esos paréntesis abiertos que atentan contra la verosimilitud en el seno de una representación no pueden reconducirse al imaginario divulgado desde las instituciones eclesiásticas.
} 


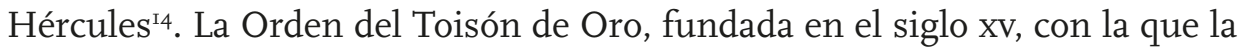
dinastía de los Habsburgo explotará su propia identificación con los míticos argonautas y el favor del Olimpo ${ }^{15}$, forma parte de la tradición de apropiarse del imaginario sobrenatural no cristiano. En suma, durante el Siglo de Oro, para dotar al poder absoluto de un aura sobrenatural que mueva a la obediencia y a la fe por conductos que escapen a la razón, los reyes no necesitan disputarse con el clero aliado el terreno de lo metafísico, sino que van a ocupar el espacio vacante de lo maravilloso profano. En las artes y en los rituales reales de la temprana modernidad se aprecia claramente cómo la monarquía busca representarse como una divinidad pagana, que sobre todo se transforma en Júpiter, cúspide de dioses, o en Apolo, deidad del orden, la armonía y la razón suprema. La deliberada confusión del plano de realidad ficticio con el epistemológico no solo es productora de una ideología determinada, sino que además trata de imponer por analogía los dogmas y los ritos que los cristianos ya tenían interiorizados a propósito de Dios. Esta consecuencia se produce por mor de un falso silogismo de varios estadios en que la monarquía comienza fagocitando el imaginario pagano para la legitimación de su poder, más tarde el ingrediente sobrenatural que contiene dicha cultura antigua provoca una elevación hasta ensamblarse con la metafísica cristiana y todo ello termina provocando una confluencia de prácticas en la población que determinará su habitus y cosmovisión, especialmente, su relación con el poder. Junto a Dios, el Estado ahora es todopoderoso, está en posesión de la Verdad y el cumplimiento de sus propósitos pasa por caminos que son inescrutables por el limitado entendimiento del género humano. La crítica entendida como disidencia o sabotaje de discursos autoritarios es necesaria para desenmascarar el andamiaje retórico que, apoyado en la fachada de la iglesia, es construido por las monarquías ávidas del poder absoluto más incondicional.

El hábitat natural de los recursos por los que el poder de la realeza invade el imaginario de lo maravilloso no cristiano es el género de la comedia mitológica del Siglo de Oro. Un buen indicio para visibilizar la inyección de discursos autoritarios en este tipo de piezas es detectar los desvíos del dramaturgo

\footnotetext{
${ }^{14}$ De hecho, según su Estoria de Espanna, fue el propio héroe mitológico quien, a propósito de la regencia de la península ibérica, "non quisso que fincasse la tierra sin omnes de so linage" (I982: 44).

Is En la pintura de Luca Giordano, Apoteosis de la Monarquía Española, para el palacio del Buen Retiro, puede verse a Hércules entregándole el toisón a Felipe el Bueno. La representación de los territorios de la corona se mezcla con deidades olímpicas y, al lado de la alegoría de España, un niño muestra las palabras omnibus unus.
} 
respecto de las fuentes antiguas y modernas de la tradición mitográfica. En La fábula de Perseo seguimos las aventuras del protagonista hasta que Lope decide detener la trama heroica, separarse de las fuentes y abrir un paréntesis prodigioso con ayuda de grandes efectos escenográficos, visuales y musicales, que provocan el pasmo del auditorio. Tras derrotar a Medusa, Perseo observa, al grito de “iProdigio extraño!" cómo de la sangre del monstruo sale el caballo Pegaso "con alas de mil colores" y realiza una ascensión desde la parte más baja del teatro a la más alta (I985: vv. I759-I762). En las alturas, de una coz hace brotar una "fuente milagrosa" de aguas cristalinas rodeada de poetas y musas que cantan. Esta brecha que interrumpe la acción narrativa del argumento tiene un objetivo primordial: alabar explícitamente a Felipe IV y a la aristocracia española mediante el prodigio que admira y arrastra al espectador. En el marco de tal espejismo, en la fuente Castalia sale a escena Virgilio lamentándose de no ser español (I985: vv. I797-I804).

En la obra titulada El vellocino de oro, Lope no desaprovecha la ocasión para acentuar el origen mítico del toisón de oro tan querido por la Casa de Austria y la identificación de sus protagonistas en un salto temporal interesado. Todas las piezas de este género dramático pueden leerse como textos que ensalzan el poder real, como estudió Margaret R. Greer (I99I) a propósito de las comedias mitológicas de Calderón. Que el espacio predilecto para la maravilla profana sea este género dramático marcadamente destinado a la corte -aunque no con carácter exclusivo-, no significa que en él se agoten los instrumentos sobrenaturales que apelan al espectador imponiéndole ese modelo de mundo que redunda en la obediencia ciega al poder hegemónico. Por función dramática oracular o recursos oraculares he denominado a todos aquellos artificios mediante los cuales una voz entendida como superior jerarquiza el aparente libre albedrío de los personajes revelando una verdad profunda que debe ser interpretada, aunque a menudo resulte confusa, porque en ella se cifra el destino de los hombres de a pie. Entre los recursos oraculares más utilizados por los dramaturgos áureos, además de los propios oráculos paganos stricto sensu, se encuentran el sueño premonitorio, la voz interior del individuo o cualquier otra iluminación transitoria, como la de muchos músicos que cantan "al azar", como víctimas de la posesión de una fuerza superior, una letra que entraña esa verdad profunda para el personaje que escucha ${ }^{\mathrm{I}}$.

\footnotetext{
${ }^{16}$ Un caso paradigmático es El caballero de Olmedo, en que el personaje se interroga acerca de esa misteriosa canción que habla de él y que el viento traslada. Para un análisis inmanente del recurso oracular aplicado a las obras de Lope, de Bances Candamo y de una selección a partir de
} 
La palabra cantada es el modo de expresión predilecto para la imposición de modelos de mundo característica de la función dramática oracular. El ingrediente musical dota a la palabra de una distinción respecto a las emanadas por parte del resto de personajes, causa la admiratio entre el público y es un medio eficaz para mover las pasiones. Asimismo, el dramaturgo entronca con una poderosa tradición que vincula la melodía con la divinidad y que arranca al menos desde la música de las esferas, de raíz pitagórica, concepción presente todavía en el Siglo de Oro, aunque reconducida a la metafísica cristiana $^{\text {17 }}$. Desmantelar este silogismo a propósito de los recursos oraculares cantados del teatro del Siglo de Oro implica reparar en que el instinto impulsivo de unión con la divinidad propio del éxtasis musical, y que se manifiesta a menudo en la danza ${ }^{18}$, es utilizado para abolir las particularidades del individuo y empujarlos a la unión con el poder. Esto también puede predicarse a cualquier recurso que cumpla con la función dramática oracular, independientemente de que su expresión sea cantada, pues no debemos olvidar que estamos ante teatro en verso, con toda la cadencia de la rima y el ritmo que imprimen musicalidad, aunque la admiración y el arrebato pasional sea en distinto grado ${ }^{\mathrm{I}}$.

distintos géneros dramáticos del Siglo de Oro, véase, respectivamente, Gilabert (20I7a, 20I7b: 215-268 y 2019).

${ }^{17}$ Bances Candamo refiere que platónicos y pitagóricos fueron aquellos "que entre la ciega filosofía gentílica inquirieron más de la divinidad” y a partir de esta premisa descubrieron "la causa de ser los racionales tan inclinados a la música, y de tener ella aquel dulce imperio de mover las pasiones" (I970: 95). En términos nietzscheanos, el poder hegemónico estaría construyendo una razón apolínea mediante el aprovechamiento de su antítesis, es decir, del carácter extático de lo dionisíaco, pues precisa de la desmesura ininteligible para generar la claridad de un orden formal constrictivo. En sus indagaciones sobre el nacimiento de la tragedia con el concurso de la música, el filósofo alemán (2000: I243) asocia a Dioniso esa fuerza de arrastre que tiene lo sonoro y destaca su enérgica asociación con lo metafísico: "La música se diferencia de todas las demás artes en que no es la reproducción de la apariencia, o mejor, de la adecuación objetiva de la voluntad, sino la imagen inmediata de la voluntad misma, y representa así, frente al elemento físico, el elemento metafísico del mundo".

I8 "Cantando y danzando se manifiesta el ser humano como miembro de una comunidad superior: ha desaprendido a andar y a hablar y está en camino de echar a volar por los aires danzando. Por sus gestos habla la transformación mágica" (Nietzsche, 2000: II78).

19 En La gaya ciencia, a propósito de la poesía, Nietzsche dice "el ritmo es una coacción, genera un ansia irresistible de ceder, de colocarse al unísono; y no sólo con los pies, sino también el alma quien sigue el compás" y más adelante "se trató por consiguiente de constreñirles mediante el ritmo y ejercer una fuerza sobre ellos, se les echaba al cuello la poesía como un mágico nudo corredizo" (I999: 97-98). 
Uno de los rasgos prototípicos del gracioso es su función metateatral, de manera que, al menos en potencia, es el agente más capacitado para sabotear un discurso represivo o señalar artificios asumidos como convención natu$\mathrm{ral}^{20}$. Por su carácter fácilmente desviable de la norma, el donaire es el único personaje que suele o no entender el mensaje enigmático o bien desconfiar de los recursos oraculares. Cuando ocurre esto es escarmentado públicamente, como el pastor Frondoso de Adonis y Venus (Vega, 20I7), que trata de engañar al oráculo y Apolo lo castiga haciéndole perder su identidad, convirtiéndolo en distintos animales. De manera que ante la voz del destino y sus agentes solo cabe la obediencia ciega o la perdición y la perspectiva del gracioso, en tanto que subalterno, da acceso a una mirada desde el margen y la disidencia.

Asensi (20II: 9) utiliza en su propuesta crítica la metáfora de la droga para hablar de esos discursos que violentan hasta alterar la percepción de la realidad. En el sistema teatral del Siglo de Oro es más frecuente hablar de veneno para el oído y, a pesar de que resulte una paradoja, los principales responsables de sabotear sus efectos son miembros del clero ${ }^{21}$. Téngase en cuenta que en el inicio de la Edad Moderna el teatro gozaba de un cómodo monopolio para formar la opinión pública mediante su viva representación, con una influencia ideológica combatida enérgicamente desde el púlpito, que contemplaba impotente cómo perdía índices de audiencia. Anatemizando la diversidad de prácticas teatrales y parateatrales de la iglesia medieval ${ }^{22}$, la ortodoxia contrarreformista había renunciado a aglutinar, educar y entretener en su seno a esa sociedad cada vez más escindida. De este modo, la opinión de la Iglesia respecto al arte dramático estará dividida entre aquellos que asocian todos los males de su tiempo a los corrales de comedias y aquellos más pragmáticos,

\footnotetext{
${ }^{20}$ Así, en El laurel de Apolo dos graciosos dan cuenta de la diferencia en el modo de expresarse ellos, como representantes de lo popular, y los dioses: mientras unos hablan otros cantan (Calderón de la Barca, I952: 2179).

${ }^{21}$ Según Camargo, las palabras venenosas de los actores "se introducen sin resistencia en el alma y, embuelta en el concepto, en la agudeza, en el artificio dulce de los versos sonoros y primorosos" y así "bebe sin horror el corazón la ponçoña" (Moir, I970: LIX). Para él, incurren en pecado mortal todos los escritores de comedias, los que aprueban y autorizan su representación y, finalmente, los que compran su entrada para verlas.

${ }^{22}$ Numerosas fueron las condenas dirigidas a las prácticas escénicas en el interior de las iglesias a lo largo de la Edad Media, como por ejemplo la que se expresa en el marco del III Concilio de Toledo "Exterminanda omnino est irreligiosa consuetudo quam vulgus per sanctorum solemnitates agere consuevit, ut populi, qui debent officia divina attendere, saltationibus et turpibus invigilent canticis [...]" (Lázaro Carreter, I98I: 2I). El Concilio de Trento puso fin a estos espectáculos con contadas excepciones, como el Misteri d'Elx, que logró una bula papal para seguir representando dentro del templo.
} 
proclives a utilizar ese nuevo canal de persuasión masiva para instruir en la ortodoxia católica. De hecho, las tablas llegaron a contar con una buena porción de su programación dedicada al dogma de la fe: no es menor la cantidad de autos sacramentales y de comedias religiosas de todo tipo (bíblicas, marianas, hagiográficas), a pesar de que fuesen interpretadas por un colectivo denostado por sectores de la Iglesia y no alcanzasen a veces el rigor teológico deseable ${ }^{23}$. Ya que no podían cerrar los teatros permanentemente y el sistema había arraigado lo suficiente como para quedarse, el poder religioso no renunció a su parcela en ese altavoz. Además, en aquellos casos en que no se hubiera observado la escrupulosidad deseada por la Iglesia, o hubiera pasajes ambiguos, tras la escritura de la obra teatral la censura velaba, con desiguales resultados, para corregir los desvíos de la norma ${ }^{24}$.

En tanto que los paradigmas que muestran los argumentos de la escena del Siglo de Oro ejercen una relación disciplinaria en los receptores ${ }^{25}$ mediante la cual pasan desapercibidas las fuentes de control, orientación y corrección de comportamientos, podemos vincular al mundo de la comedia la tecnología de poder propia del panoptismo según la idea que Foucault desarrolla en $\mathrm{Vi}$ gilar y castigar (2002: II8-I37). La censura teatral, responsable de revisiones e intervenciones en los textos áureos, sería una más de las prácticas institucionales dedicadas a la vigilancia y al castigo sin ser percibidas por el espectador. Aun así, esa institución represiva y su ideología es mucho más consciente y detectable que la del dramaturgo que toma como punto de partida aparentemente neutral un abanico de personajes parcialmente estereotipados que por sí mismos ya están sugiriendo los lugares que les corresponden en ese microcosmos dramático que tanto se parece o debería parecerse al theatrum mundi.

\footnotetext{
${ }^{23}$ En un pasaje del Quijote, Cervantes pone en boca del cura el siguiente comentario sobre las comedias no religiosas de su tiempo: "Y aun en las humanas se atreven a hacer milagros, sin más respeto ni consideración que parecerles que allí estará bien el tal milagro y apariencia, como ellos llaman, para que gente ignorante se admire y venga a la comedia" (2005: 496). Estos milagros son los que, bajo mi punto de vista, utiliza el poder civil, a menudo para ejecutar una función dramática oracular.

${ }^{24}$ El cronista Barrionuevo anotó en sus Avisos que la comedia Vida y muerte de san Cayetano, "estando para hacerse, la recogió la Inquisición. No creo tienen cosa contra la fe, si bien lo apócrifo debe de ser mucho", pero, a instancias de la reina, no tardó en reponerse "habiéndola primero escudriñado muy bien la Inquisición" (Gilabert, 2020).

${ }_{25}^{25}$ El sujeto, antes de participar en un ritual determinado como el teatro, ya ha aceptado previamente la ideología que va a consumir, de manera que no la estaría percibiendo como algo externo. Incluso si el individuo mantiene cierta distancia con relación al ritual, de manera inconsciente "éste lo domina ya desde dentro" (Žižek, 2007: I4).
} 


\section{Conclusiones}

Hoy en día la escena sigue siendo la plataforma que mejor puede expresar el aquí y el ahora de la manera más inmediata, aunque el número de espectadores haya ido reduciéndose a lo largo de los siglos en la medida en que se ha ido multiplicando la oferta de ocio para el consumo masivo. Sin embargo, en los inicios de la Edad Moderna gozaba de un cómodo monopolio con relación al control de la opinión pública. Es precisamente en el paso de la Edad Media a la Moderna cuando se abre una gran crisis que amenaza los privilegios de la clase dominante que va a ver en la práctica escénica una oportunidad para legitimarse. Los manuales de historia de la literatura española, en los capítulos dedicados al teatro del Siglo de Oro, destacan la creación de "un teatro nacional" con esta fórmula repetida hasta la saciedad que viene a aludir a ese sistema dramático pensado para que la colectividad se vea reflejada y embelese transversalmente a todos, con independencia de la posición social de cada uno. No obstante, deberíamos sospechar automáticamente de un medio de comunicación de masas en un régimen absolutista causante de grandes desigualdades sociales que, en la imagen que proyecta de la realidad, guste tanto a opresores y a oprimidos. Como se ha demostrado a partir del poder subversivo de la crítica entendida como sabotaje, la percepción inducida refleja un sentido que alaba un estado de cosas del que sale beneficiada y reforzada la ideología hegemónica.

Desenmarañar la ideología de los textos no les resta un ápice de valor estético. Es más, podemos decir que el teatro del Siglo de Oro representa una cumbre estética dentro de la historia de la literatura europea y los textos que perviven hoy dan fe de la enorme fuerza dramática que tienen sus argumentos, personajes y versos, un vasto océano que se aprecia en cada comedia desde su primer verso hasta el giro que suele darse en la última escena, en que todo ese potencial es encauzado por la convención hacia una resolución y una moraleja altamente conservadoras. Es lógico que la recepción por parte del público teatral iletrado sea una obsesión del poder, tanto civil como eclesiástico. La controversia sobre la licitud de las comedias atestigua esta preocupación y da cuenta de ejemplos de trasvase de materiales desde las tablas hasta fuera de los corrales ${ }^{26}$.

\footnotetext{
${ }^{26}$ Así, Crespí se quejaba de que en las comedias "se cantan cosas con cifras lascivas, pero tan claras que los niños las entienden, y las aprenden y las cantan por las calles, no sin detrimento grande de algunas doncellas que las oyen, ni sin ofensión de los oídos castos" (Bances Canda-
} 
Finalmente, en este trabajo se han sentado las bases de la función dramática oracular, cimentada en una serie de recursos en los que una voz superior jerarquiza a las demás y representa una verdad revelada de tipo secular que marcará el destino de los personajes de la trama. Con estos artificios retóricos se pretende arrastrar al espectador a una obediencia ciega al poder civil, como si su voz fuera la de una deidad que no admitiese la razón o el juicio propio. Este conjunto de recursos oraculares se ven potenciados cuando se aúna la poesía con la música y se invoca la capacidad irracional de lo sonoro para mover las pasiones. Un pasaje en que se inserta el elemento sobrenatural de la maravilla no cristiana en la cotidianidad del marco dramático y que cumple con la función oracular construye un poderoso discurso que impone una modelización de mundo en aras de la deificación de la autoridad del rey. Ante tal bombardeo de discursos culturales, podríamos decir, junto a Nietzsche, que «las verdades son ilusiones cuyo carácter ficticio ha sido olvidado» ${ }^{27}$.

El análisis crítico-lingüístico demuestra ser un acto de obstrucción de los mecanismos ideológicos, de manera que siguen siendo necesarios los filólogos, lectores y críticos en general para desenmascarar las inercias de un sistema que violenta a los sujetos en un plano que es simbólico solo temporalmente, pues sus efectos sobre la realidad están latentes, esperando que el mundo sugerido sea naturalizado.

\section{Bibliografía}

Alfonso X. I982. Estoria de España. Antología. Madrid: Porrúa Turanzas.

Althusser, Louis. 1974. Ideología y aparatos ideológicos de Estado. Buenos Aires: Nueva Visión.

Asensi Pérez, Manuel. 20II. Crítica y sabotaje. Barcelona: Anthropos.

Bances Candamo, Francisco. 1970. Theatro de los theatros de los passados y presentes siglos. Edición de Duncan W. Moir. Londres: Tamesis Books.

Calderón de la Barca, Pedro. 1995. La vida es sueño. Edición de Evangelina Rodríguez Cuadros. Madrid: Espasa Calpe.

mo, I970: 30). El mismo desasosiego por la formación moral del vulgo espectador muestra el cura del Quijote, para quien su ideal de comedia debe producir una serie de efectos concretos en los receptores (2005: 496).

${ }_{27}$ “¿Qué es, entonces, la verdad? Un dinámico tropel de metáforas, metonimias y antropomorfismos; en suma, un conjunto de relaciones humanas que, realzadas, plasmadas y adornadas por la poesía y la retórica, y tras un largo uso, un pueblo considera sólidas, canónicas y obligatorias; las verdades son ilusiones cuyo carácter ficticio ha sido olvidado" (Nietzsche, 2008: 274). 
Calderón de la Barca, Pedro. I952. El laurel de Apolo. En Valbuena Briones, Ángel (ed.) Obras completas I. Madrid: Aguilar, 2I7I-2I95.

Cervantes, Miguel de. 2005. Don Quijote de la Mancha. Edición de Francisco Rico. Madrid: Alfaguara.

Derrida, Jacques. 1986. De la gramatología. México D. F.: Siglo XXI.

Fontana, Josep. 2000. Europa ante el espejo. Barcelona: Crítica.

Foucault, Michel. 2002. Vigilar y castigar. Buenos Aires: Siglo XXI.

Gilabert, Gaston. 2020. "Prólogo". En Diamante, Juan Bautista et alii. Vida y muerte de san Cayetano. Edición de Gaston Gilabert. Alicante: Biblioteca Virtual Miguel de Cervantes.

Gilabert, Gaston. 20I9. Poesía cantada como presagio de muerte en el teatro del Siglo de Oro. En Di Pinto, Elena (ed.) Delito y muerte en el teatro del Siglo de Oro. Madrid: Visor, 89-I05.

Gilabert, Gaston. 20I7a. I will play the swan and die in music: Shakespeare y Lope de Vega ante la música teatral trágica. Anuario Lope de Vega XXIII: 270-285.

Gilabert, Gaston. 2orjb. Música y poesía en las comedias de Bances Candamo. Vigo: Editorial Academia del Hispanismo.

Gramsci, Antonio. I975. Quaderni del carcere. Turín: Einaudi.

Greer, Margaret Rich. I991. The Play of Power: mythological Court Dramas of Calderón de la Barca. Princeton: Princeton University Press.

Lázaro Carreter, Fernando. I981. Teatro Medieval. Madrid: Castalia.

Loyola, San Ignacio de. I963. Obras completas de San Ignacio de Loyola. Edición de Ignacio Iparraguirre. Madrid: Biblioteca de Autores Cristianos.

Maravall, José Antonio. I972. Teatro y literatura en la sociedad barroca. Madrid: Seminarios y Ediciones.

Moir, Duncan W. I970. Introducción. En Bances Candamo, Francisco. Theatro de los theatros de los passados y presentes siglos. Edición de Duncan W. Moir. Londres: Tamesis Books.

Nietzsche, Friedrich. 2008. Sobre verdad y mentira en sentido extramoral. Madrid: Tecnos.

Nietzsche, Friedrich. 2000. El origen de la tragedia a partir del espíritu de la música. En Obras inmortales III. Barcelona: Edicomunicación, II6I-I284.

Nietzsche, Friedrich. I999. La gaya ciencia. Madrid: Edimat.

Said, Edward W. 2007. Orientalismo. Barcelona: DeBolsillo.

Vega, Lope de. 20I7. Adonis y Venus. Blanco, Mercedes \& Joannon, Felipe Joannon (eds.) Comedias de Lope de Vega. Parte XVI I. Coordinación de Florence D’Artois $\&$ Giuliani, Luigi. Madrid: Gredos, 213-380.

Vega, Lope de. 20i6. Arte nuevo de hacer comedias. Edición de Felipe B. Pedraza Jiménez \& Conde Parrado, Pedro (eds.). Cuenca: Ediciones de la Universidad de Castilla-La Mancha.

Vega, Lope de. I985. La fábula de Perseo o La bella Andrómeda. Edición de Michael D. McGaha. Kassel: Reichenberger.

Vega, Lope de. I965. El rústico del cielo. En Menéndez Pelayo, Marcelino (ed.) Obras de Lope de Vega XI. Madrid: Atlas, 397-462.

Žižek, Slavoj. 2007. El acoso de las fantasías. México D. F.: Siglo XXI. 